\title{
Correlates of joint child protection and police child sexual abuse investigations: results from the Canadian Incidence Study of Reported Child Abuse and Neglect-2008
}

\section{Tonmyr, PhD (1); A. Gonzalez, PhD (2)}

This article has been peer reviewed.

Tweet this article

\section{Abstract}

Introduction: Our study examines the frequency of joint investigations by child protection workers and the police in sexual abuse investigations compared to other maltreatment types and the association of child-, caregiver-, maltreatment- and investigation-related characteristics in joint investigations, focussing specifically on investigations involving sexual abuse.

Methods: We analyzed data from the Canadian Incidence Study of Reported Child Abuse and Neglect-2008 using logistic regression.

Results: The data suggest that sexual abuse (55\%), and then physical abuse, neglect and emotional maltreatment, are most often co-investigated. Substantiation of maltreatment, severity of maltreatment, placement in out-of-home care, child welfare court involvement and referral of a family member to specialized services was more likely when the police were involved in an investigation.

Conclusion: This study adds to the limited information on correlates of joint child protection agency and police investigations. Further research is needed to determine the effectiveness of these joint investigations.

Keywords: child abuse, child sexual abuse, child maltreatment, police, child protection worker

\section{Introduction}

Child maltreatment is a challenging problem that requires multidisciplinary approaches to solving it. The social determinants of health almost exclusively fall outside the traditional health sector, and this is particularly true for child maltreatment as a health issue. ${ }^{1}$ Both police officers and child protection workers are mandated to protect children from harm, and since the late 1960s the police have actively collaborated with social workers to protect children from maltreatment. ${ }^{2}$ Joint investigations involving child protection services and the police are consistent with a public health approach to addressing child maltreatment. In fact, the World Health Organization champions multisectoral collaboration as an important component in preventing child maltreatment and improving the health of children. ${ }^{3}$ Such joint investigations have led to increased communication and cooperation between the police and child protection agencies, with the development of written policies, interagency agreements and multidisciplinary teams.

Although a body of literature investigating the attitudes and perceptions of interagency collaborations exists, data examining characteristics of joint investigations
Key findings

- Sexual abuse is the maltreatment category most often jointly investigated by child protection and police, followed by physical abuse, neglect and emotional maltreatment.

- We found that substantiation of maltreatment, severity of maltreatment, placement in care, involvement of the child welfare court and referrals of a family member to specialized services were more likely in joint investigations.

are limited. An increased understanding of what factors are associated with joint investigation may help inform future practice and policy standards.

All Canadian jurisdictions have protocols on how and when joint investigations should take place; however, the type and level of collaboration varies, as it does in the United States (US). ${ }^{4}$ For instance, in Alberta, under the Criminal Code of Canada, child protection workers report to the police if they think an offence has been committed. ${ }^{5}$ In British Columbia, when a police officer has reasonable grounds to believe that a child's safety or well-being is in immediate danger, the officer has the authority to take charge of the child and notify a child protection worker as quickly as possible. ${ }^{6}$

One example of collaboration in Canada are the Child Advocacy Centres, which have been funded by the Department of Justice since 2010 and which are currently being 
evaluated. ${ }^{7}$ Similar centres in the US have been shown to be effective. ${ }^{8}$ These childfocussed centres include teams representing law enforcement, child protection services, prosecution, mental health services, victim advocacy services and child advocacy. ${ }^{8}$

Investigations tend to exist on a continuum: formal joint investigations, where these two groups of professionals must collaborate about certain types of maltreatment; informal joint investigations, where they may work together; and separate investigations, which state one or the other is solely responsible for the investigation. ${ }^{9}$ Formal joint investigation protocols are most common for physical and sexual abuse. ${ }^{9}$ The goals of these joint investigations are to (1) reduce the child's discomfort and trauma by decreasing the number of interviews; ${ }^{10}$ and (2) to better protect the child by improving evidence-gathering through increased communication among professionals. ${ }^{10,11}$

Both child protection workers and police officers have raised several concerns to do with their joint involvement in child maltreatment investigations. Stanley et al. ${ }^{12}$ found that the police have a limited understanding of what child protection workers do with the information the police give them. Similarly, police officers expressed concern about delays by child protection workers in informing them about cases, ${ }^{12}$ as well as their attitudes, job performances and capacity to make decisions. ${ }^{2}$ According to Holdaway, ${ }^{13}$ child protection workers are not always available when needed, leaving the police with unresolved problems (e.g. a parent is arrested in the early morning hours and their child is in need of shelter). Conversely, child protection workers were concerned about the police moving too quickly and believed that they were not responsive to constructive criticism. ${ }^{14}$ In addition, police culture sometimes clashed with child protection workers' anti-discriminatory and anti-oppressive attitudes. ${ }^{2}$ Interviews conducted with children were cited as the main source of conflict between the police and child protection workers. ${ }^{14}$ Organizational constraints, such as different working hours, dissimilar geographical areas of jurisdiction and a lack of resources added to the difficulties in collaboration. Each organization felt their professional identity could erode over time. ${ }^{14}$
TABLE 1

Description of variable used in the Canadian Incidence Study of Reported Child Abuse and Neglect-2008

\begin{tabular}{ll}
\multicolumn{1}{c}{ Variable $^{\mathrm{a}}$} & \multicolumn{1}{c}{ Description } \\
\hline Joint investigation & $\begin{array}{l}\text { Level of police involvement in the current child welfare investigation: } \\
\text { investigation only, charges considered and charges laid }\end{array}$ \\
Sexual abuse & $\begin{array}{l}\text { The child had been sexually molested or sexually exploited. This } \\
\text { could include penetration, attempted penetration, oral sex, } \\
\text { fondling, sex talk or images, voyeurism, exhibitionism, } \\
\text { exploitation and other sexual abuse }\end{array}$
\end{tabular}

Physical abuse

The child was physically harmed or could have suffered physical harm because of the behaviour of the person looking after the child. Codes included shake, push, grab, throw, hit with hand, punch, kick, bite, hit with object, choke, poison, stab and other physical abuse

Neglect The child has been harmed or the child's safety or development has been endangered as a result of a failure to provide for or protect the child. Codes included failure to supervise, leading to physical harm; failure to supervise, leading to sexual abuse; permit criminal behaviour; physical neglect; medical/dental neglect; failure to provide psychological treatment; abandonment; and educational neglect

Emotional maltreatment

The child had suffered, or was at substantial risk of suffering, emotional harm caused by the person looking after the child. Codes included terrorizing, threatening violence, verbal abuse, belittling, isolation, confinement, inadequate nurturing, exploitation, corrupting behaviour and exposure to non-partner violence

Exposure to IPV

The child directly witnessed violence between intimate partners; was indirectly exposed to violence (overhears but does not see; or sees some of the immediate consequences, e.g. injuries; or the child is told or overhears conversations about the assault); and was exposed to emotional violence between intimate partners

Multiple type

Any type of sexual abuse co-occurring with another category of maltreatment

Primary caregiver substance (alcohol and/or drug) abuse present

If the child protection worker or another worker diagnosed, disclosed, observed, had documented in the file or at the conclusion of the investigation thought it was likely that the primary caregiver abused alcohol and/or drugs

IPV confirmed/suspected

If the child protection worker suspected or confirmed that the primary or secondary caregiver was a victim or perpetrator of domestic violence

Child's sex

Male/female

Alleged perpetrator age

40 years or younger vs 41 years or older

Alleged perpetrator sex

Alleged perpetrator

Male/female

Primary caregiver, secondary caregiver or "other person",

Substantiated maltreatment

Child maltreatment was confirmed after an investigation by a child protection worker

Harm

Physical and/or emotional harm

Severity

The child required therapeutic treatment for mental/emotional harm and/or medical treatment and/or their health/safety was seriously endangered

Referral

At least one referral for services for any family member

Abbreviation: IPV, intimate partner violence.

Note: The selection of variables was guided by the work of Cross et al. ${ }^{17}$ as well as by hypotheses about factors that would increase the likelihood of a joint investigation.

${ }^{\text {a }}$ We have described the relationship in those investigations where sexual abuse was the sole category of maltreatment.

Despite these challenges, joint investigations have their advantages. Working collaboratively improves communication between police officers and child protection workers. Both professional groups share information more equally, plan more 
comprehensively, support each other and bring distinctive skills, knowledge and experience to an investigation. ${ }^{14}$

The benefits of working together can also occur at an individual level. Child protection workers felt safer in potentially dangerous situations when police officers were present. ${ }^{2}$ In addition, police officers are legally permitted to use force in particular circumstances, which justifies requests for their presence when addressing high-risk family conflicts. ${ }^{13}$ Furthermore, working closely together promotes understanding of the other agency's function, importance and competencies. Child protection workers reported learning more about the criminal justice system from the police, ${ }^{14}$ whereas from child protection workers the police learned more about communicating with children, including using appropriate language and incorporating toys and play to increase children's comfort in engaging with them. ${ }^{15}$ Joint investigations can also spare the child repeat interviews. ${ }^{4,16}$

Knowledge about the characteristics of joint investigations is sparse. One U.S. study found that the majority of sexual abuse investigations were a joint effort (45\%) compared to other types of investigations including physical abuse $(28 \%)$ and neglect (18\%). ${ }^{17}$ The credibility of an allegation was strongly predicted by police involvement in the investigation. In addition, caregiver alcohol and/or drug abuse, the severity of abuse, and active domestic violence often increased police involvement. Moreover, it was more likely that services would be provided to the child/ family if there was a police investigation. ${ }^{17}$

No such study has been conducted in Canada. A case vignette study that assessed attitudes towards incidents of incest found that the police focussed on collecting evidence whereas child protection workers concentrated on the safety of the child and long-term implications for the family. ${ }^{18}$ However, although hypothetical vignettes are important, they fail to address the complexities involved in decision making and may not reflect what actually occurs.

Given this shortage of information regarding children investigated by child welfare, the Public Health Agency of Canada (PHAC) and partners initiated the Canadian Incidence Study of Reported Child Abuse and Neglect (CIS), which provides a unique opportunity to investigate police involvement with child protection agencies using multivariate techniques.

We used CIS data in this study in order to examine the frequency of joint child protection worker and police investigations into sexual abuse cases compared to other maltreatment types, and to examine the association of child-, caregiver-, maltreatment- and investigation-related characteristics in joint investigations, focussing on investigations involving sexual abuse. Although joint investigations can occur for all types of child maltreatment, we focus on sexual abuse since all jurisdictions across Canada have developed joint protocols for sexual abuse. ${ }^{5,619-28}$

\section{Methods}

Data source

The data used came from the Canadian Incidence Study of Reported Child Abuse and Neglect-2008 (CIS-2008). ${ }^{29}$ The CIS was developed by PHAC with its partners to obtain estimates of child maltreatment reported to child protection agencies across Canada. The CIS was approved by McGill University's Ethics Committee. Details of the methodology of the CIS are outlined elsewhere. $^{29}$ In brief, the study used a multistage, stratified, cluster design to acquire a sample of investigations from all 13 jurisdictions in Canada. For 2008, data were collected from October 1 to December 31, 2008, from 112 of 412 agencies. Child protection workers provided information for each child investigated using a standardized CIS three-page form four to six weeks after the initial report to the agency. Researchers provided a half-day training course on how to complete the form. Researchers were also available to answer any questions throughout the data collection period.

\section{Measures}

The selection of variables was guided by the work of Cross et al. ${ }^{17}$ as well as by hypotheses about factors that would increase the likelihood of a joint investigation (see Table 1). ${ }^{29}$ Types of maltreatment included exposure to intimate partner violence (IPV), emotional abuse, neglect, physical abuse and sexual abuse. In the CIS, up to three were collected for each child.

\section{Statistical analysis}

We included only child maltreatment investigations in our analysis. Investigations focussed on "risk of future maltreatment" were excluded, as were investigations involving youth over 15 years as 15 is the oldest age for which child protection services are provided in some jurisdictions. Given that little is known about the characteristics of sexual abuse investigations that involve police, this analysis was largely exploratory. Proportions, or means and standard deviations (SD), were described for all variables of interest. Colinearity

\begin{tabular}{|c|c|c|c|c|}
\hline \multirow{4}{*}{ Primary child maltreatment } & \multicolumn{4}{|c|}{$\begin{array}{l}\text { TABLE } 2 \\
\text { ild maltreatment in joint child welfare and police } \\
\text { investigations }\end{array}$} \\
\hline & \multicolumn{4}{|c|}{ Joint investigations } \\
\hline & \multicolumn{2}{|c|}{ No } & \multicolumn{2}{|c|}{ Yes } \\
\hline & $\mathbf{N}$ & $\%$ & $\mathbf{N}$ & $\%$ \\
\hline Exposure to IPV & 2562 & 94.4 & 153 & 5.6 \\
\hline Emotional abuse & 1001 & 92.2 & 85 & 7.8 \\
\hline Neglect & 3915 & 90.0 & 436 & 10.0 \\
\hline Physical abuse & 2340 & 79.0 & 621 & 21.0 \\
\hline Sexual abuse & 308 & 44.4 & 386 & 55.6 \\
\hline
\end{tabular}

Abbreviation: IPV, intimate partner violence. 
TABLE 3

Profiles of maltreatment categories in sexual abuse investigations in joint child welfare and police investigations

\begin{tabular}{lcr}
\multicolumn{1}{c}{ Distribution of maltreatment categories } & N & \% \\
\hline Sexual abuse only & 573 & 68.1 \\
Sexual abuse and neglect & 128 & 15.2 \\
Sexual abuse and physical abuse & 43 & 5.1 \\
Sexual abuse and emotional abuse & 23 & 2.7 \\
Sexual abuse and exposure to IPV & 23 & 2.7 \\
Sexual abuse and neglect and emotional abuse & 13 & 1.5 \\
Sexual abuse and neglect and exposure to IPV & 13 & 1.5 \\
Sexual abuse and physical abuse and emotional abuse & 8 & 1.0 \\
Sexual abuse and physical abuse and exposure to IPV & 8 & 1.0 \\
Sexual abuse and physical abuse and neglect & 7 & 0.8 \\
Sexual abuse and emotional abuse and exposure to IPV & - & - \\
\hline
\end{tabular}

Abbreviation: IPV, intimate partner violence.

- Estimates of $<5$

between independent variables was tested using chi-square or correlations. Bivariate associations between each variable and the outcome were tested with logistic regression. Due to the large sample size, the criterion for significance was as follows: the increase in predictive power between the model with only a constant and the model with the single variable had to equal or exceed Cox and Snell $R^{2}$ of .01 . Independent variables that had a significant bivariate relationship with police involvement were considered for entry into the model. Various models were tested to determine the most parsimonious model that would explain the greatest proportion of variance in police involvement.

TABLE 4

Characteristics of child and primary caregiver in joint child welfare and police investigations

\begin{tabular}{|c|c|c|c|c|c|c|}
\hline & \multicolumn{6}{|c|}{ Joint investigations } \\
\hline & \multicolumn{2}{|c|}{ Yes } & \multicolumn{2}{|c|}{ No } & \multicolumn{2}{|c|}{ Total } \\
\hline & $\mathbf{N}$ & $\%$ & $\mathbf{N}$ & $\%$ & $\mathbf{N}$ & $\%$ \\
\hline \multicolumn{7}{|l|}{ Sex of child } \\
\hline Male & 120 & 27.4 & 179 & 44.3 & 299 & 35.5 \\
\hline Female & 318 & 72.6 & 225 & 55.7 & 543 & 64.5 \\
\hline Total & 438 & 100.0 & 404 & 100.0 & 842 & 100.0 \\
\hline \multicolumn{7}{|l|}{ Substance abuse by primary caregiver } \\
\hline Suspected/confirmed & 16 & 3.7 & 12 & 3.0 & 28 & 3.3 \\
\hline No & 422 & 96.3 & 392 & 97.0 & 814 & 96.7 \\
\hline Total & 438 & 100.0 & 404 & 100.0 & 842 & 100.0 \\
\hline Mean (SD) age of child age, years & \multicolumn{2}{|c|}{$9.1(4.2)$} & \multicolumn{2}{|c|}{$8.4(4.0)$} & \multicolumn{2}{|c|}{$8.8(4.1)$} \\
\hline
\end{tabular}

Abbreviation: SD, standard deviation.
In all models, variables were entered in one step. Analyses were run in SUDAAN (SUDAAN for Windows, version 7.5.3, Research Triangle Institute, NC, USA), which makes variance adjustments for the correlated data resulting from the survey's design. The nesting variables were agency and family.

\section{Results}

Including child maltreatment investigations of those aged under 16 years resulted in a sample of 11807 . Table 2 includes the entire sample to show police involvement in the investigation of the five maltreatment

types. Compared with investigations of exposure to IPV (reference), emotional maltreatment was 1.4 times (95\% CI: 1.1-1.9) more likely to have police involved in the investigation, neglect about twice as likely (odds ratio $[\mathrm{OR}]=1.9 ; 95 \% \mathrm{CI}: 1.5-2.2$ ), physical abuse 4.5 times as likely ( $95 \%$ CI 3.8-5.4) and investigations of sexual abuse about 21 times more likely to have police involvement (OR $=20.9$; 95\% CI: 16.8-26.9). About $55 \%$ of sexual abuse investigations were conducted jointly (see Table 2).

Of the 11807 investigations, 842 had sexual abuse as one of the three categories of maltreatment. Table 3 shows that over twothirds of cases were sexual abuse without co-occurring maltreatment (68.1\%), followed by sexual abuse and neglect (15.2\%). Fondling (32.3\%) and other sexual abuse $(27.2 \%)$ occurred most frequently, followed by penetration $(8.3 \%)$, sex talk or images $(3.7 \%)$, oral sex $(3.3 \%)$, exhibitionism $(2.7 \%)$ and attempted penetration $(2.0 \%)$. Voyeurism occurred in less than $1 \%$ of the sample. Information on what acts constituted "other sexual abuse" were not available.

Investigations of female victims were twice as likely to have the police involved (OR = 2.1; 95\% CI: 1.6-2.9) (see Table 4). Having more than one subtype of sexual abuse $(\mathrm{OR}=2.2$; $95 \% \mathrm{CI}: 1.3-3.6)$, severe maltreatment $(\mathrm{OR}=2.9$; $95 \% \mathrm{CI}: 1.8-4.5)$ or evidence of harm (OR $=3.5$; 95\% CI: $2.3-$ 5.3 ) increased the likelihood of police involvement (see Table 5). Investigations where the alleged perpetrator was identified as "other person" (someone other than the primary or secondary caregiver; $\mathrm{OR}=1.8$; 95\% CI: 1.2-2.6; primary caregiver reference category) or involved a male alleged perpetrator $(\mathrm{OR}=1.9$; $95 \% \mathrm{CI}: 1.3-2.8)$, were more likely to involve police.

Family members as well as peers were the “other persons" most commonly involved in joint investigations where sexual abuse was the sole investigation of maltreatment (see Table 6).

Police involvement in the investigation was associated with an increased likelihood that the case would be substantiated $(\mathrm{OR}=4.5$; 95\% CI: 3.1-6.6), that the child would be placed or considered to be placed into care 
TABLE 5

Characteristics of child maltreatment and related variables in child welfare and police investigations

\begin{tabular}{|c|c|c|c|c|c|c|}
\hline & \multicolumn{6}{|c|}{ Joint investigations } \\
\hline & \multicolumn{2}{|c|}{ Yes } & \multicolumn{2}{|c|}{ No } & \multicolumn{2}{|c|}{ Total } \\
\hline & $\mathbf{N}$ & $\%$ & $\mathbf{N}$ & $\%$ & $\mathbf{N}$ & $\%$ \\
\hline \multicolumn{7}{|c|}{ Sexual abuse only vs sexual abuse with other maltreatment } \\
\hline Multitype & 125 & 28.5 & 144 & 35.6 & 269 & 31.9 \\
\hline Sexual abuse alone & 313 & 71.5 & 260 & 64.4 & 573 & 68.1 \\
\hline Total & 438 & 100.0 & 404 & 100.0 & 842 & 100.0 \\
\hline \multicolumn{7}{|c|}{ Number of subtypes of sexual abuse } \\
\hline One & 357 & 81.5 & 366 & 90.6 & 723 & 85.9 \\
\hline More than one & 81 & 18.5 & 38 & 9.4 & 119 & 14.1 \\
\hline Total & 438 & 100.0 & 404 & 100.0 & 842 & 100.0 \\
\hline \multicolumn{7}{|c|}{ Intimate partner violence in the home } \\
\hline Yes & 39 & 8.9 & 41 & 10.1 & 80 & 9.5 \\
\hline No & 399 & 91.1 & 363 & 89.9 & 762 & 90.5 \\
\hline Total & 438 & 100.0 & 404 & 100.0 & 842 & 100.0 \\
\hline \multicolumn{7}{|l|}{ Severity } \\
\hline Severe & 112 & 25.6 & 43 & 10.6 & 155 & 18.4 \\
\hline Not severe & 326 & 74.4 & 361 & 89.4 & 687 & 81.6 \\
\hline Total & 438 & 100.0 & 404 & 100.0 & 842 & 100.0 \\
\hline \multicolumn{7}{|l|}{ Harm } \\
\hline Yes & 131 & 29.9 & 44 & 10.9 & 175 & 20.8 \\
\hline No & 307 & 70.1 & 360 & 89.1 & 667 & 79.2 \\
\hline Total & 438 & 100.0 & 404 & 100.0 & 842 & 100.0 \\
\hline \multicolumn{7}{|l|}{ Alleged perpetrator } \\
\hline Primary caregiver & 95 & 21.7 & 120 & 29.7 & 215 & 25.6 \\
\hline Secondary caregiver & 60 & 13.7 & 76 & 18.8 & 136 & 16.2 \\
\hline Other person ${ }^{a}$ & 282 & 64.5 & 208 & 51.5 & 490 & 58.3 \\
\hline Total & 437 & 100.0 & 404 & 100.0 & 841 & 100.0 \\
\hline \multicolumn{7}{|c|}{ Sex of alleged perpetrator } \\
\hline Male & 345 & 80.6 & 268 & 72.6 & 613 & 76.9 \\
\hline Female & 83 & 19.4 & 101 & 27.4 & 184 & 23.1 \\
\hline Total & 428 & 100.0 & 369 & 100.0 & 797 & 100.0 \\
\hline \multicolumn{7}{|c|}{ Age of alleged perpetrator, years } \\
\hline$<16$ & 11 & 2.7 & 21 & 6.0 & 32 & 4.2 \\
\hline $16-18$ & 50 & 12.3 & 31 & 8.8 & 81 & 10.7 \\
\hline $19-21$ & 49 & 12.1 & 20 & 5.7 & 69 & 9.1 \\
\hline $22-30$ & 68 & 16.7 & 58 & 16.5 & 126 & 16.6 \\
\hline $31-40$ & 126 & 31.0 & 122 & 34.8 & 248 & 32.8 \\
\hline$\geq 41$ & 102 & 25.0 & 99 & 28.1 & 201 & 26.5 \\
\hline Total & 406 & 100.0 & 351 & 100.0 & 757 & 100.0 \\
\hline
\end{tabular}

${ }^{a}$ Not primary or secondary caregiver.

during the investigation $(\mathrm{OR}=2.8 ; 95 \%$ CI: 1.4-5.6), that a referral to services would be made for the family ( $\mathrm{OR}=1.6$; $95 \%$ CI: 1.1-2.9) and that child welfare court would become involved (OR $=3.2 ; 95 \%$ CI: 1.7-5.9) (see Table 7).
On examining colinearity between variables with significant associations with police involvement, we found that 36 of the 66 pairs of independent variables predictors were significantly related at $\alpha=.05$. Most notable were the associations between alleged perpetrator type-primary caregiver, secondary caregiver, other personand their sex and between harm and severity. Perpetrator type explained 59\% of the variance in perpetrator sex, and severity explained $47 \%$ of the variance in harm. Due to the high colinearity between these variables, we tested models that included either alleged perpetrator type or sex and harm or severity and were chosen based on goodness of fit. The most parsimonious model is shown in Table 8 . A female victim, a male alleged perpetrator, the presence of harm and case substantiation were significantly associated with police involvement.

\section{Discussion}

Our study adds to the sparse information on correlates of joint child protection agency and police investigations. Consistent with prescribed protocols, we found that sexual abuse $(55 \%)$ is the maltreatment category most often jointly investigated by child protection and police, followed by physical abuse, neglect and emotional maltreatment. This is similar to findings from USA and the United Kingdom. ${ }^{14,16,17,30}$

Being female (for the victims) and male (for the perpetrators) are established risk factors for child sexual abuse ${ }^{31}$ and are associated with police involvement. Most research indicates that females are exposed to sexual abuse more often than are males. ${ }^{31}$ However, others argue that sexual abuse of male victims is underreported..$^{32}$

We found no differences in police involvement in sexual abuse investigations with different ages of the victims. Investigations with and without police involvement focussed on pre-adolescents. It is possible that it is easier to gather information from these children and that they may be seen as more credible sources of information. ${ }^{33}$ Furthermore, sexual abuse of pre-adolescents may be seen as more serious and that of adolescents may be less likely to be reported.

Investigations of sexual abuse by the "other person" most often included family members or peers as perpetrators. This is consistent with research that shows that in 
TABLE 6

Distribution of the "other person"" as alleged perpetrator in joint child welfare and police investigations where sexual abuse is the sole category of maltreatment

\begin{tabular}{|c|c|c|c|c|c|c|}
\hline & \multicolumn{6}{|c|}{ Joint investigations } \\
\hline & \multicolumn{2}{|c|}{ Yes } & \multicolumn{2}{|c|}{ No } & \multicolumn{2}{|c|}{ Total } \\
\hline & $\mathbf{N}$ & $\%$ & $\mathbf{N}$ & $\%$ & $\mathbf{N}$ & $\%$ \\
\hline $\begin{array}{l}\text { Biological or step- or common-law mother/father or adoptive/ } \\
\text { foster parent }\end{array}$ & 41 & 20.7 & 30 & 21.1 & 71 & 20.9 \\
\hline Grandparent, uncle, aunt or other relative & 48 & 24.2 & 14 & 9.9 & 62 & 18.2 \\
\hline $\begin{array}{l}\text { Sibling/foster sibling, cousin, boyfriend/girlfriend, child's friend } \\
\text { or peer }\end{array}$ & 59 & 29.8 & 47 & 33.1 & 106 & 31.2 \\
\hline Family friend, babysitter/babysitter's family, neighbour or boarder & 25 & 12.6 & 17 & 12.0 & 42 & 12.4 \\
\hline $\begin{array}{l}\text { Recreational staff, maintenance staff, daycare provider, coach, } \\
\text { teacher or other professional }\end{array}$ & 7 & 3.5 & 0 & 0 & 7 & 2.1 \\
\hline Stranger/Unknown/Other & 18 & 9.1 & 34 & 23.9 & 52 & 15.3 \\
\hline Total & 198 & 100.0 & 142 & 100.0 & 340 & 100.0 \\
\hline
\end{tabular}

${ }^{a}$ Not primary or secondary caregiver.

TABLE 7

Investigation-related characteristics in joint child welfare and police sexual abuse investigations

\begin{tabular}{|c|c|c|c|c|c|c|}
\hline \multirow[t]{3}{*}{ Investigation-related characteristic } & \multicolumn{6}{|c|}{ Joint investigations } \\
\hline & \multicolumn{2}{|c|}{ Yes } & \multicolumn{2}{|c|}{ No } & \multicolumn{2}{|c|}{ Total } \\
\hline & $\mathbf{N}$ & $\%$ & $\mathbf{N}$ & $\%$ & $\mathbf{N}$ & $\%$ \\
\hline \multicolumn{7}{|l|}{ Substantiated sexual abuse } \\
\hline No & 260 & 59.4 & 351 & 86.9 & 611 & 72.6 \\
\hline Yes & 178 & 40.6 & 53 & 13.1 & 231 & 27.4 \\
\hline Total & 438 & 100.0 & 404 & 100.0 & 842 & 100.0 \\
\hline \multicolumn{7}{|c|}{ Case previously opened for any family member } \\
\hline Yes & 211 & 49.4 & 225 & 56.7 & 436 & 52.9 \\
\hline No & 216 & 50.6 & 172 & 43.3 & 388 & 47.1 \\
\hline Total & 427 & 100.0 & 397 & 100.0 & 824 & 100.0 \\
\hline \multicolumn{7}{|l|}{ Placement } \\
\hline Considered/placed & 40 & 9.3 & 14 & 3.5 & 54 & 6.5 \\
\hline None & 392 & 90.7 & 389 & 96.5 & 781 & 93.5 \\
\hline Total & 432 & 100.0 & 403 & 100.0 & 835 & 100.0 \\
\hline \multicolumn{7}{|l|}{ Referral for any family member } \\
\hline Yes & 255 & 58.2 & 190 & 47.0 & 445 & 52.9 \\
\hline No & 183 & 41.8 & 214 & 53.0 & 397 & 47.1 \\
\hline Total & 438 & 100.0 & 404 & 100.0 & 842 & 100.0 \\
\hline \multicolumn{7}{|l|}{ Child welfare court } \\
\hline Some involvement & 45 & 10.3 & 14 & 3.5 & 59 & 7.0 \\
\hline No involvement & 393 & 89.7 & 390 & 96.5 & 783 & 93.0 \\
\hline Total & 438 & 100.0 & 404 & 100.0 & 842 & 100.0 \\
\hline \multicolumn{7}{|c|}{ Police involved in adult IPV investigation } \\
\hline Some involvement & 24 & 5.7 & 16 & 4.0 & 40 & 4.9 \\
\hline No involvement & 399 & 94.3 & 384 & 96.0 & 783 & 95.1 \\
\hline Total & 423 & 100.0 & 400 & 100.0 & 823 & 100.0 \\
\hline
\end{tabular}

Abbreviation: IPV, intimate partner violence. most instances the victim knows the perpetrator. For example, in a representative U.S. survey, Finkelhor et al. ${ }^{34}$ found that acquaintances perpetrated sexual abuse $91 \%$ of the time compared to $7 \%$ for strangers and $2 \%$ for family. These findings are not directly comparable to our results as the above study is population based, whereas our study focusses on children known to child protection.

Several service-related variables were significantly related to joint investigations. Like Cross et al., ${ }^{17}$ we found that substantiation of maltreatment, severity of maltreatment, placement in care, involvement of the child welfare court and referrals of a family member to specialized services were more likely in joint investigations. We can only speculate on the reasons, given the nature of the data, but the mandate of joint investigations is to ensure safety and protection of children. This can involve providing evidence to the court for removal of the child to care or punishment of the perpetrator, ${ }^{18}$ but it can also encompass the provision of services to improve parenting capacity whether it includes alcohol and/or drug counselling or receipt of financial assistance or childfocussed services. Cross et al. ${ }^{17}$ suggested that the additional services offered in joint investigations may indicate that police involvement does not, in fact, cause a greater distress that hampers the relationship with the investigated families or change the focus of child protection agencies' mandate to assist children and families. Instead, this could be a reflection of the increased closeness of police and the public as a result of the movement towards community policing. ${ }^{35}$

Contrary to findings by Cross et al., ${ }^{17}$ we did not find substance abuse and IPV of the primary caregiver to be associated with an increased likelihood of police involvement-although their findings were not specific to sexual abuse but were across maltreatment types. It may be that other caregiver risk factors, not included in these analyses, such as maternal age, caregiver mental health and the presence of a stepfather ${ }^{36,37}$ are related to increased likelihood of police involvement. 
TABLE 8

Full regression model of joint child welfare and police sexual abuse investigations

\begin{tabular}{lcccc}
\multicolumn{1}{c}{ Contrast } & Degrees of freedom & Wald & $\boldsymbol{p}$ value & OR (95\% Cl) \\
\hline Overall model & 5 & 18.90 & $<.0001$ & \\
Model minus intercept & 4 & 18.69 & $<.0001$ & \\
Intercept & - & - & - & $0.41(0.27-0.63)$ \\
Substantiated case (yes) & 1 & 26.68 & $<.0001$ & $2.85(1.92-4.25)$ \\
Alleged perpetrator sex (male) & 1 & 8.10 & .0046 & $1.83(1.21-2.78)$ \\
Harm (yes) & 1 & 8.39 & .0039 & $2.01(1.25-3.22)$ \\
Sex of child (female) & 1 & 9.37 & .0023 & $1.65(1.20-2.27)$ \\
\hline
\end{tabular}

Abbreviations: $\mathrm{Cl}$, confidence interval; OR, odds ratio.

Note: Cox \& Snell $R^{2}=.16$

\section{Strengths and limitations}

Although the CIS has several strengths, there are limitations that may influence the conclusions that can be drawn from the data. In fact, the CIS

- collects information on children reported to child protection agencies and thus underestimates the occurrence of maltreatment;

- portrays the clinical opinion of child protection workers, which are not independently verified;

- gathers data during three months in the fall, which may not be representative of the year; and

- uses a cross-sectional design, which precludes establishing causation.

\section{Conclusion}

The results of this analysis suggest that, of all categories of reported maltreatment, sexual abuse is most likely to involve joint investigations. Although, continued collaboration between specialized groups of child protection workers and police may be appropriate, the potential benefits of this synergistic approach need to be monitored and evaluated. Little is known about its effectiveness in Canada. Although more is known about joint investigations in the US, the Canadian context may be different due to the legal system and jurisdictional issues. Also, some authors ${ }^{30}$ speculate whether child protection agencies have gone too far in the investigative process and have moved away from the critical matters of prevention and treatment. This question merits attention, although the present analysis suggested that more services were provided after joint investigations. The roles of other professions on multidisciplinary teams such as those within the health sector also require further attention.

More research is needed to investigate the effectiveness of joint investigations, for instance, has there been a decline in the number of times a child is interviewed? Has information-sharing between police and child protection increased? Would it be beneficial to the health of the child to have joint investigations more often for the other types of maltreatment than happens currently? These questions need to be answered in order to increase our understanding of collaborative investigations and their potential to benefit victims of child maltreatment.

Responding to child maltreatment with multidisciplinary teams will assist in an integrated response through primary and secondary prevention of child maltreatment and associated negative health outcomes, surveillance, increased public awareness, development of best practices and evaluation of programs, especially considering that children and their families received more services when investigations were joint. It is promising to see that joint investigations take place in the intended circumstances as per provincial and territorial protocols.

\section{Acknowledgements}

The authors gratefully acknowledge the assistance of Jasminka Draca, Dr. David Hubka, Ellen Jamieson, Joanne Lacroix and Caroline Wallace.

\section{References}

1. Tonmyr L, MacMillan H, Jamieson E, Kelly K. The population health perspective as a framework for studying child maltreatment outcomes. Chronic Dis Can. 2002;23(4):123-9.

2. Garrett PM. Talking child protection: the police and social workers 'working together' J Soc Work. 2004;4(1):77-97.

3. Butchart A, Harvey AP, Mian M, Furniss T. Preventing child maltreatment: a guide to taking action and generating evidence. Geneva $(\mathrm{CH})$ : World Health Organization; 2006. Joint publication of the International Society for Prevention of Child Abuse and Neglect.

4. Winterfeld AP, Sakagawa T. Investigation models for child abuse and neglect - Collaboration with law enforcement. Englewood (CO): American Humane Association; 2003.

5. Government of Alberta. Responding to child abuse: a handbook [Internet]. Edmonton (AB): Government of Alberta; 2005 [cited 2013 June 20]. Available from: http://justice.alberta.ca/programs_services/families/ Documents/responding_to_child_abuse_ handbook_2006.pdf

6. Government of British Columbia. The B.C. handbook for action on child abuse and neglect for service providers [Internet]. Victoria (BC): Government of British Columbia; 2005 [cited 2013 June 20]. Available from http://www.mcf.gov.bc.ca/child_protection/ pdf/handbook_action_child_abuse.pdf

7. McDonald S, Scrim K, Rooney L. Building our capacity: children's advocacy centres in Canada [Internet]. Victims of Crime Research Digest. 2013 [modified: 2015 Jan 7; cited 2015 Jan 29];6:2-11. Available from: http://www.justice.gc.ca/eng/rp-pr/cj-jp/ victim/rd6-rr6/p2.html

8. Jones LM, Cross TP, Walsh WA, Simone M. Do children's advocacy centers improve families' experiences of child sexual abuse investigations? Child Abuse Negl. 2007;31: 1069-85.

9. Moran-Ellis J, Fielding N. A national survey of the investigation child sexual abuse. Brit J Soc Work. 1996;26:337-56

10. Sheppard DI, Zangrillo PA. Coordinating investigations of child abuse. Public Welfare. 1996;54(1):21-31. 
11. Jones LM, Cross TP, Walsh WA, Simone M. Criminal investigations of child abuse: the research behind "best practices". Trauma Violence Abuse. 2005;6(3):254-68.

12. Stanley N, Miller P, Foster HR, Thomson G. Children's experiences of domestic violence: developing an integrated response from police and child protection services. J Interpers Violence. 2011;26(12):2371-91.

13. Holdaway S. Police and social work relations - problems and possibilities. Brit J Soc Work. 1986;16:137-60.

14. Lloyd S, Burman M. Specialist police units and the joint investigation of child abuse. Child Abuse Review. 1996;5:4-15.

15. Brown L, Fuller R. Central Scotland's joint police and social work initiative in child abuse: an evaluation. Child Soc. 1991;5(3):232-240.

16. Tjaden PG, Anhalt J. The impact of joint law enforcement child protective services investigations in child maltreatment cases. Denver (CO): Centre for Policy Research; 1994.

17. Cross TP, Finkelhor D, Ormrod R. Police involvement in child protective services investigations: Literature review and secondary data analysis. Child Maltreat. 2005;10(3):224-44.

18. Trute B, Adkins E, MacDonald G. Professional attitudes regarding treatment and punishment of incest: community police, child welfare and community mental health. J Fam Violence. 1996;11(3):237-49.

19. Government of Manitoba. Child and family services manual [Internet]. Winnipeg (MB): Manitoba Family Services and Housing: 2008 Jul 2 [updated 2008 Oct 10; cited 2013 June 20]. Available from: http://www.gov. mb.ca/fs/cfsmanual/pubs/pdf/1.3.7_enp.pdf

20. Government of New Brunswick. Child victims of abuse and neglect: protocols [Internet]. Fredericton (NB): Government of New Brunswick; 2005 Mar [cited 2013 June 20]. Available from: http://www2.gnb.ca/content/dam/gnb/Departments/sd-ds/pdf/Protection/Child/ChildAbuseProtocols05-e.pdf

21. Government of Newfoundland and Labrador. Children and youth care and protection act [Internet]. St. John's (NL): Government of Newfoundland and Labrador; 2010 [updated 2010 Jun 24; cited 2013 June 20]. Available from: http://www.assembly.nl. ca/legislation/sr/statutes/c12-2.htm
22. Government of Northwest Territories. Child and family services act [Internet]; 2011 [cited 2013 June 20]. Available from: http:// www.canlii.org/en/nt/laws/stat/snwt-1997c-13/latest/part-1/snwt-1997-c-13-part-1.pdf

23. Government of Nova Scotia. Children and family services act [Internet]. Halifax (NS): Government of Nova Scotia; 2008 [cited 2013 June 20];[Screen 1]. Available from: http://www.novascotia.ca/just/regulations/ regs/cfsregs.htm

24. Government of Prince Edward Island. Child sexual abuse protocol: guidelines and procedures for a coordinated response to child sexual abuse in Prince Edward Island [Internet]. Charlottetown (PEI): Government of Prince Edward Island; 2013 [cited 2013 June 20]. Available from: http://www.gov. pe.ca/photos/original/CSA_PROT_2013.pdf

25. Government of Quebec. Chapter P-34.1 Youth protection act [Internet]. Québec (QC): Government of Quebec; 2013 [cited 2013 June 20]. Available from: http://www2.publicationsdu quebec.gouv.qc.ca/dynamicSearch/telecharge. php?type $=$ 2\&file = /P_34_1/P34_1_A.HTM

26. Government of Saskatchewan. Provincial child abuse protocols [Internet]. Regina (SK): Government of Saskatchewan; 2014 [cited 2015 September 23]. Available from: https://www.saskatchewan.ca/government/ news-and-media/2014/october/29/revisedchild-abuse-protocol

27. Government of Yukon. Children's act [Screen 132] [Internet]. Whitehorse (YK): Government of Yukon; 2002 [cited 2013 June 20]. Available from http://www.gov. yk.ca/legislation/acts/childrens.pdf

28. Gough P. Ontario's child welfare system [Internet]. Toronto (ON): Centre of Excellence for Child Welfare; 2005 [cited 2015 Jan 29]. Available from: http://cwrp.ca/ sites/default/files/publications/en/OntChildWelfareSystem31E.pdf

29. Public Health Agency of Canada. Canadian Incidence Study of Reported Child Abuse and Neglect 2008: major findings. Ottawa (ON): Public Health Agency of Canada; 2010. Available from: http://www.phacaspc.gc.ca/cm-vee/csca-ecve/2008/assets/ pdf/cis-2008_report_eng.pdf

30. Sanders R, Jackson S, Thomas N. The police role in the management services of child protective services. Polic Soc. 1996;6:87-100.
31. Hanson RF, Borntrager C, Self-Brown S, et al. Relations among gender, violence exposure, and mental health: The national survey of adolescents. Am Journal Orthopsychiatr. 2008;78(3):313-21.

32. Smith LH, Ford J. History of forced sex and recent sexual risk indicators among young adult males. Perspect Sex Repro H. 2010;42 (2):87-92.

33. King CB, Scott KL. Why are suspected cases of child maltreatment referred by educators so often unsubstantiated? Child Abuse Negl. 2014;38:1-10.

34. Finkelhor D, Ormrod R, Turner H, Hamby SL. The victimization of children and youth: a comprehensive, national survey. Child Maltreat. 2005;10(1):5-25.

35. Thomas T. The police and social workers: creativity or conflict. Practice Soc Work Action. 1988;2(2):120-9.

36. Gilbert R, Widom CS, Browne K, Fergusson D, Webb E, Janson S. Burden and consequence of child maltreatment in highincome countries. Lancet. 2009;373:68-81.

37. Gonzalez A, MacMillan HL. Preventing child maltreatment: an evidence-based update. J Postgrad Med. 2008;54:280-6. 